\title{
ENGLISH - ITS PLACE AND USE AS A MEDIUM OF INSTRUCTION AT THE LAND FORCES ACADEMY OF SIBIU
}

\author{
Georgeta OBILIŞTEANU \\ "Nicolae Bălcescu" Land Forces Academy, Sibiu, Romania \\ pusa_obi@hotmail.com
}

\begin{abstract}
The process of European and international integration has led to an increase of the English language use, turning it into the main means of communication at a global level. Thus, having a good command of the English language has become a necessity for every person, being a student's first option. It is a priority both for the military personnel and undergraduates. In this context, the curricula of the military higher education have included English as a foreign language (EFL) as a compulsory discipline. In addition to this, it has gained in importance with the introduction of an international semester for the cadets attending the Military Leadership program of study, where all the subjects are taught in English. The main issue in using English as a medium of instruction in the teaching of particular subject matters is that this must be done in a correct manner so that it does not result in failure in the educational process. This paper points to the way English is used in the Land Forces Academy and offers some guidelines for specialists in producing their own teaching materials. Some examples are provided from teaching English for specific purposes, in our case military basic English.
\end{abstract}

KEYWORDS: instruction, English foreign language, mobility, multinational operations

\section{Introduction}

English is the most widely used language on earth, being the main means of communication in business, trade, administration, science, technology, diplomacy, etc. Recognizing its major role in the European integration and the need to meet the demands of the competitive labor market, it has turned into the first choice of a student within the educational system in most countries of the European Union and the world.

In the Land Forces Academy, the important place English holds can be seen from its implementation as a mandatory discipline in the curriculum and in its use in conveying specialized knowledge in a number of specific military fields.
The academy has contributed to the development of several international projects. Also, the two scientific publications, included in the international data bases EBSCO and ProQuest - the Land Forces Academy Review and the Scientific Bulletin - provide experts and practitioners in specialized fields with the opportunity to publish in English the results of their research and survey studies in the following fields: behavioral and social sciences; economic sciences; economic and juridical sciences; national defense; national and international security; military leadership; intercultural education; electronic and cyber warfare; crisis management; higher education e-learning; Euro-Atlantic integration. 
In addition, there are international events, such as the Knowledge-Based Organization International Conference (KBO) and the Students' International Conference Secosaft, which represent great opportunities for presentations and disseminations of the results obtained by our teachers and students in the field of scientific research, as well as for promoting ideas and mutual information between military and civilian teachers and students.

\section{The Place of English in the Academy}

In order to allow the academic teaching staff and research specialists to come together and exchange ideas on a variety of topics, the Land Forces Academy made its contribution to developing different projects:

- ERASMUS + Strategic Partnership - "Creating international semester regarding military education needs for future officers in Europe";

- ERASMUS + Program;

- European Initiative on the Exchange of Young Officers inspired by ERASMUS Program;

- European Researchers' Night: Marie Sklodowska-Curie Actions;

- Cultural Understanding and Language Proficiency Program (CULP);

- International Military Academic Forum.

In 2014, the Academy obtained the Erasmus Charter for Higher Education 20142020, developing and continuing partnerships with higher education institutions. It signed bilateral agreements with academies and universities of many European countries: Austria, Belgium, the Czech Republic, Bulgaria, Hungary, Poland, Italy, Portugal, Slovakia, Turkey, Greece.

In order to meet the needs of future officers in Europe, through the abovementioned international program of study, subjects such as: interoperability, cultural awareness, military leadership, intercultural communication, comprehensive approach, law of armed conflict and electronic warfare are delivered in English and the materials being used are common to the cadets of the five countries that are part of it.

Since the Romanian military higher education system has been actively engaged in the ERASMUS and the ERASMUS + Programs for teachers and students, mastering the English language at a proficient 32 eone3232 a requirement that the military personnel and undergraduates must meet.

In this context, using English as a medium of instruction for transmitting advanced knowledge in particular fields must be done in a correct manner, as MariaMiruna Ciocoi-Pop put it, "Through these programs, the Romanian higher education promotes multilingualism, multiculturalism and diversity but, at the same time, acknowledging the binding role of the English language in this context. The issue is more than teaching English as a foreign language, it is teaching English correctly, as a medium for the education process..." (Ciocoi-Pop, 2015, p. 287).

Transmitting advanced knowledge is not an easy task for the teachers who are specialists in particular fields of study, but who lack the necessary English language competence. Therefore, in the Land Forces Academy, the specialists' linguistic abilities are tested before being assigned to teach concepts and ideas specific to their disciplines.

\section{Guidelines for Materials Writing in Teaching English for Specific Purposes \\ Each person acquires the common language before approaching the specialized language. Today, along with the general language every speaker employs at least one specialized language, which represents his professional field or personal interest. Therefore, teaching English for Specific Purposes (ESP) has to be considered within the larger context of}


teaching general English both in terms of the teacher's role and of materials writing and methodology.

An important aspect that differentiates the general English teachers from the teachers of ESP consists in the need that the ESP teachers will have to address of designing and writing the course materials his students will use in learning. As Tom Hutchinson and Alan Waters clearly formulated, "It is likely that in addition to the normal functions of a classroom teacher, the ESP teacher will have to deal with needs analysis, syllabus design, materials writing or adaptation and evaluation" (Hutchinson \& Waters, 1993, p. 157).

In designing their specialized course, the would-be ESP teachers must decide on the following aspects: the subject-matter area and the topics needed 33 eone 3333 the proposed content, how this content is organized throughout the course (by topic, study skills or a combination of them); how the content is organized within each unit of the course (by means of a set of patterns, or focusing on developing certain skills); the sequence of the content in each unit (from comprehension to production, from accuracy to fluency); the types of didactic activities/tasks necessary (language or skills practice 33 eone33, comprehension or production, role play, simulation exercises); the teaching-learning techniques to be used (lockstep, pair-work, group-work, student presentations, whole class debates); available aids (audio-cassettes, video camera, overhead projector), the flexibility the materials lend themselves to (allowing for the choice of a different order or following the given order, as well as the possibility of linking them to other contentrelated materials).

Throughout the course material, there need to be coherence in terms of both language and content. Besides the internal coherence, the course structure must be consistent with the syllabus structure, making sure that all the items of the syllabus are covered by the course material so that the specific objectives can be achieved by the learners.

Not only the content of what the learners have to acquire is important, but also the didactic activities and tasks through which this is learnt. The syllabus design starts from the students' needs and interests and the course specific objectives have to aut the outcomes to be achieved by the students. In order to maximize the way learning takes place in the classroom, the materials should allow for flexible use, enabling teachers to adjust them to the particular group of students they are working with.

\subsection{Types of Tasks Used in Teaching Military Basic English}

In drawing up the didactic tasks, the content, language structures, vocabulary, functions have to be identified (specialized vocabulary, active/passive voice, nominal compounds, modal verbs, transitional words, description of equipment or systems).

Since the main goal in learning a foreign language 33 eon use language correctly, in the case of teaching military basic English the materials writer should produce interactive tasks that provide opportunities for learners to use their existing knowledge both of the language and the subject matter. Thus, the identified elements can be practised through tasks such as:

- a transfer activity in which students extract the needed information from a text 33 eone 33 it in speaking or in filling aut the table in bullet form;

- a gap-filling activity where students listen to or read a document and fill in the gaps with the missing information;

- a matching exercise requiring learners to aut pictures with equipment items, words with their meanings, military facilities with the activities being held in them); 
- a description exercise requiring students to provide an oral or written description of equipment (for example, an individual weapon in use or a military vehicle in service in our country);

- a reconstruction activity in which students have to use the bits of information they have been provided with at a certain stage of the lesson by listening to/reading a passage and then render the message conveyed;

- a jigsaw exercise where students have to unstumble the sentences in order to form a meaningful, coherent paragraph.

An example of a transfer activity employed in teaching military basic English to cadets can 34 eone in which the teacher gives students a set of cards with accounts of different military careers. It is carried aut as a pair-work speaking activity where one student extracts relevant information from the information about the soldier on the card he has chosen and answers the interlocutor's questions about that military career. At the same time they have to complete a table like the one below:

\begin{tabular}{|l|}
\hline Name: \\
\hline Rank: \\
\hline Initial education: \\
\hline Educational qualifications and promotion: \\
\hline Plans for further education: \\
\hline
\end{tabular}

The following matching exercise can help cadets acquire or reinforce the vocabulary related to the process of military decision-making that military commanders resort to in the conduct of operations on the battlefield:

Match the words on the left with the definitions on the right.
1. mission
a. to officially give out or make available
2. to brief
b. a rough or approximate calculation
3. to assign
c. to give someone a particular job or duty
4. staff
d. a combat operation assigned to a unit
5. operations plan
e. a command given by a commander to troops
6. to issue
f. personnel; a group of people working for a unit
7. order
g. to give instructions or essential information
8. estimate
h. formal plan drawn up by a commander for the conduct of operations during a military conflict

In order to give cadets practice in developing the skill of listening for specific information, they can be asked to listen to a recording/watch a video and fill in the gaps with the missing information. The following can be taken as an example:

Listen to the presentation of a Field Training Exercise and complete the sentences with the missing information.

\section{Tape script}

(1:48) In the news it's often the execution of a mission you hear about. You really hear about the hours of preparation it took to make that mission possible. Those preparations or troopleading procedures were the focal point of the $4^{\text {th }}$ Brigade, $10^{\text {th }}$ Mountain Division recent field training exercise. Mission TLPs are very involved processes during which all considerations for ammo and supplies are meticulously thought out.

If you are not meticulous and going through the little things now, then those are the things that are going to get you killed in combat. If we are not training that way, then we see ourselves up for failure, so we have to be meticulous now so that when being meticulous really counts - in Afghanistan lives weren't lost. 
Something else that happens during TLPs is just about anything that can happen during the mission has a contingency plan built for it to soldiers that have practiced reacting to those situations until it becomes second nature.

Things get messy quickly, so you need to be able to react, you really need to be able to think. Going through these drills helps us just make quick decisions without thinking. So you can get in there, accomplish the mission, get out and arrive home safely.

Even though the troop-leading procedures are designed to prepare a unit practically for what they may face, for many soldiers troop-leading procedures give them the confidence they need to perform.

We are very confident to deploy with this group of individuals. I actually got them training and actually worked with the platoon and I enjoyed the training they have been through - the regulars, the repetition. I'm very confident.

1. Troop-leading procedures are very involved processes during which all considerations for ammo and supplies are meticulously thought out.

2. Soldiers have to be meticulous during the preparation for a mission as the little things will get them killed in combat.

3 . They have to practice reacting to different situations until it becomes second nature.
4. Going through $\underline{d r i l l s}$ helps soldiers make quick decisions without thinking.

5. The troop-leading procedures give many soldiers the confidence they need to perform.

The tasks we have chosen illustrate the types of didactic activities that ESP practitioners can employ in designing their own teaching and learning resources to be used by learners in acquiring the key concepts and ideas of specific fields and in reinforcing the knowledge of the subject matter.

\section{Conclusions}

The impact the English foreign language has had in the Land Forces Academy on the evolution of the educational-instructional process has been great in the last few years. The academic teaching staff is concerned with the way the EFL will further influence the military higher education community that will continue to be engaged in intercultural relations. Since the influence of EFL will continue to grow in the forthcoming future, the academies and universities will have to do their best to adapt their curricula and syllabuses to the current demands coming from the labor market, in our case to the kind of military multinational operations and missions cadets/future officers will take part in on the international theatres of operations.

\section{REFERENCES}

Ciocoi-Pop, M.-M. (2015). A general overview of English as a foreign language in the contemporary Romanian higher education. The $21^{\text {st }}$ International Conference The KnowledgeBased Organization, Conference Proceedings 2 Economic, Social and Administrative Approaches to the Knowledge-Based Organization, Sibiu: Editura Academiei Forţelor Terestre „Nicolae Bălcescu”, 287.

Hutchinson, T., \& Waters, A. (1993). English for Specific Purposes A learning-centred approach. Cambridge: Cambridge University Press. 